\title{
Die Machtbestrebungen des Kardinalkollegiums gegenüber dem Papsttum.
}

Von

\author{
Jean Lulvès.
}

Machtbestrebungen des Kardinalats ${ }^{1}$ ) konnten sich naturgemäß erst entwickeln, als die Gesamtheit der römischen Kardinäle, deren ursprüngliche Stellung und Tätigkeit ich hier als bekannt voraussetzen darf, sich zu einer erkennbaren Korporation auszubilden begonnen hatte. Das geschah, als der römische Bischof nicht nur, kraft der Weltbedeutung seiner Stadt, Primas des Abendlandes geworden war, sondern auch als Territorialherrscher eine bedeutsame Stellung in Mittel-Italien erlangt hatte. Sein Presbyterium erhielt allmählich die Bestimmung - im Weiterausbau der Ideen eines Nicolaus I., Johann VIII. und Leo IX. - die Vertretung der Gesamtkirche zu werden - eine Bestimmung, die allerdings nie vollständig erfüllt worden ist.

Der Zusammenschluß des Kardinalats und seine Abgrenzung nach außen beginnt in der Mitte des 11. Jahrhunderts sich auszugestalten. Dieser Beginn wird gekennzeichnet durch den Versuch Nikolaus' II. von 1059, die nunmehr auch politisch wichtig gewordene Papstwahl

1) Vortrag, gehalten am 19. September 1914 in der XIII. Versammlung Deutscher Historiker zu Wien; hier an einzelnen Stellen erweitert, gibt er in der Hauptsache eine Übersicht über den einleitenden Teil meiner demnächst erscheinenden größeren Publikation, die das angegebene Thema behandelt. Bezüglich der Äußerungen in der Diskussion sei auf den ,Bericht über die XIII. Versammlung، (1914) S. 25 verwiesen. - Die folgenden Noten beschränken sich vornehmlich nur auf Quellenzitate an besonders bemerkenswerten Stellen. 
in geordnete Bahnen überzuleiten. Den Kardinalbischöfen war die eigentliche Entscheidung zugewiesen. Damit war der weite Abstand bezeichnet, der noch zwischen Kardinalbischöfen und den übrigen Ordines, den Kardinalklerikern, bestand. Unverkennbar ist dabei auch der scharfe Gegensatz zwischen den Bischöfen überhaupt als Trägern der geistlichen Hierarchie und den in die hierarchische Ordnung sich hineindrängenden Kardinälen. Innerhalb der Kardinals-Ordines macht sich der Gegensatz bei den nächsten Papstwahlen geltend und führt, während des folgenden Jahrhunderts, zu schweren Kämpfen, die wiederholt in strittigen Doppelwahlen zum Ausdruck kamen.

Noch in der Periode der allmähligen Ausgleichung dieses Gegensatzes, die erst 1179 durch die Dekretale Alexanders III. ,Licet in vitanda abgeschlossen erscheint, versuchen bereits die Kardinäle in die Machtsphäre des Papsttums einzugreifen, während das vorher weltliche Gewalthaber getan hatten, die auch jetzt noch häufig hinter den Kardinälen standen. Stellung und Macht des Kardinalats, von dem allein in seiner Gesamtheit hier die Rede sein kann, sowie die Stellung der Kardinäle, lediglich als Gehilfen des römischen Bischofs, hatten ihre Wurzeln im Papsttum. Wandte sich der Kardinalat nun gegen seinen Nährstamm, so unterband er seine eigene Kraft. Die Stütze, welche der Kardinalat etwa in fremden Mächten fand, war nie von kirchlichen Interessen getragen. Sie versagte deshalb sehr bald.

Von Gregor VII. fielen in seinem Streite mit König Heinrich IV. 1084 dreizehn Kardinalpriester und -diakone ab. Nach dem Berichte des Kardinals Beno beriefen sie sich dabei auf die Sentenz: Petri Bindeund Lösegewalt ruhe nicht im Papst allein, sondern im ganzẹn römischen Stuhl, d. h. im Kardinalskolleg. Dem Richterspruch der Kardinäle unterliege die ganze Welt. Sie allein, nicht die Bischöfe, richteten über den Papst, als Vertreter der sedes Romana 1). I liese Prätension zeigte also zugleich eine Spitze gegen die Bischöfe. - Durch Gregors energische Intervention hatten damals die Kardinalbischöfe mit jenen anderen Kardinälen nicht gemeinsame Sache gemacht und sie blieben in dem Streite, der sich gegen den Absolutismus Gregors richtete, Sieger; sie retteten das Papsttum und erhielten es in der gregorianischen Tradition. Jener Kampf und der Versuch jener Kardinäle, den Papst von seiner Höhe zu verdrängen, bildeten nur eine folgenlose Episode.

Stellung und Bedeutung des Kardinalats in den einzelnen Pontifikaten waren wohl von dem Vorhandensein energischer, führender Per-

1) J. Schnitzer, Die Gesta Romanae ecclesiae des Kard. Beno (1892), 93 f.; Libelli de lite II, p. 369 ff., 404, 418 . 
sönlichkeiten abhängig, mehr aber noch von der Individualität des jeweiligen Pontifex. Danach schwankte der Wert der in päpstlichen Urkunden stehend gewordenen Formel, cum ,consilio fratrum nostrorum, öfters unter Beifügung des, consensus', der wirkliche Wert der seit dem 11. Jahrhundert ${ }^{1}$ ) in päpstlichen Urkunden häufiger vorkommenden Tnterschriften der Kardinäle als Beweis der Zustimmung. Jene Formel bezeichnet weniger das tatsächliche Finflußgebiet der Kardinäle, den Ausdruck ihrer freien Meinung, sondern die Ressorts ihrer gewohnheitsmäßigen Mitarbeit an der dem Papste zustehenden kirchlichen und sonstigen Verwaltung, wie sie in den Konsistorien zu Tage trat, an den sogenannten ,causae arduae' oder, causae consistoriales' ${ }^{2}$ ).

Die Befugnisse einer entscheidenden Ratsversammlung hatte das Konsistorium nicht. Niemals ist seine Tätigkeit durch päpstliche Konstitutionen umschrieben oder festgelegt worden. Wie alle beratenden Organisationen strebte es naturgemäß nach der Kompetenz, das, was es selbst vorgeschlagen und empfohlen hatte, auch möglichst verwirklicht zu sehen. Das gelang den Kardinälen wohl unter schwachen oder sogenannten parlamentarischen Päpsten. Diplomatisch gewandte Autokraten hingegen, wie ein Bonifaz. VIII. und Johann XXII, wußten, die sogenannten Gewohnheitsrechte des Kollegiums wenigstens scheinbar respektierend, sich doch über Willen und Ansehen der Kardinäle hinwegzusetzen.

Sicherlich waren viele unter den Kardinälen, besonders die wirklich religiösen und sittenstrengen Charaktere, für die Interessen der Kirche stärker erfüllt, als für die Machttendenzen des Kollegiums. Aber diese wurden selten von der Gesamtheit außer Acht gelassen, wenn letztere auch häufig genug von politischen Parteiungen durchsetżt war. -

An die von Beno überlieferten Ansprüche klingen, wenn auch wohl nur unbewußt, die Prätensionen der Kardinäle gegenüber dem unerfahrenen Eugen III. an. Da bezeichnen sich die Kardinäle nach der Namensdeutung des Kardinal Deusdedit zum ersten Male als Axen der Gesamtkirche ${ }^{3}$ ). Ihre Vorhaltungen gegenüber dem Papst sind zugleich von dem Unmute über dessen Lehrer Bernhard von Clairvaux eingegeben, über seine und der französischen Bischöfe unbefugte Einmischung in Glaubensfragen, über seine ihnen geltenden Vorwürfe, über seine

1) Vgl. H. Breßlau, Handbuch der Urkundenlehre I 1 (1889), 710.

2) Aufgezählt bei J. B. Sägmüller, Tätigkeit und Stellung der Kardinäle bis Papst Bonifaz VIII. (1896), S. 46 ff.

s) H. Grauert, Magister Heinrich der Poet, S. 237 (Abhandl. der bayr. Akademie 1912). 
Ratsehläge, betreffend die Ergänzung ihres Kollegiums nach universellen. Gesichtspunkten.

Allerdings sprach aus Bernhards streng kurialistischer Auffassung nicht bloß der iedal gesinnte Mönch, sondern auch der für italienisches: Wesen verständnislose Franzose - ein nationaler Gegensatz, der in. der Kardinalatsgeschichte wiederholt zu folgenschwerem Durchbruch gekommen ist.

Entsprechend der zunehmenden Zentralisation der kirchlichen Verwaltung an der Kurie, entsprechend der durch Päpste wie Alexander III. und Innocenz III. betonten Überordnung der geistlichen Gewalt über die weltliche, erweiterte sich die ordnungsmäßige Tätigkeit der Kardinäle im Konsistorium. Alexander und Innocenz bemühten sich, die Stellung der Kardinäle äußerlich zu heben, ihr einen möglichst universellen Charakter zu geben, aber ohne ihnen selbst einen wirklichen Einfluß auf ihre Entschlüsse zu gestatten.

Die Bedeutung, welche sich einzelne Kardinäle durch ihre persönlichen Eigenschaften, durch solbst gewonnenen Einfluß erwarben, strahlte indirekt auf. die ganze Korporation zurück.

Die Legationen, in denen Kardinäle zeitweise Vorrechte des von. ihnen vertretenen Papstes und eine selbständige Stellung gegenüber geistlichen Ordinarien und den weltlichen Mächten ihres Legationssprengels genossen, boten ihrem Ehrgeize und ihren finanziellen Wünschen weiten Spielraum zur Betätigung, verschafften ihnen selbst Gelegenheit zu politischer Schulung. In vielfacher Rückwirkung trugen die Legationen zur Hebung des gesamten Kardinalats bei.

Mit der steigenden Weltbedeutung des Papsttums wuchs in weiterem Maße der politische Wert des Kardinalskollegs für Staaten und Herrscher Mittel- und Süd-Europas. Diese, in Sonderheit damals Frankreich und England, suchten für ihre Interessen Anhänger und Vertreter beim Papste in seinem Ratskollegium zu gewinnen, durch Pfründen, Pensionen und sonstige Geschenke, - womöglich die Aufnahme von Prälaten ihres Vertrauens durchzusetzen.

Hörten schon die alten Gegensätze der römischen Adelsfamilien, wenn diese auch von der unmittelbaren Papstwahl verdrängt waren, nie auf, im Kollegium lebendig zu sein, so wurde dieses nunmehr der Schauplatz neuer politischer Parteistreitigkeiten, besonders .im Daseinskampf des Papsttums gegen die Hohenstaufen. Wie vordem für die deutschen Könige und Kaiser aus dem Hause der Salier, so war schon für Friedrich Barbarossa eine starke Opposition unter den Kardinälen gegen die päpstliche Politik wirksan. Das hatte Hadrian IV. erfahren müssen, als er 1156 mit dem Normannen-König. Wilhelm I. von Sizilien. 
den Vertrag von Benerent abschloB, durch den er ihn als bevorrechteten päpstlichen Lehnsmann für sein erweitertes Reich anerkannte. Die Entzweiung des h. Kollegiums, die Parteiungen der Kaiserlichen und der" Sizilianer, ward Schuld an der Doppelwahl des Jahres 1159, aus der das Haupt der letzteren, Kardinal Roland, des Kaisers Gegner, schlieblich als Sieger hervorgehen sollte (Alexander III.).

In stärkerem Maße noch als Friedrich I. und sein Sohn Heinrich VI., wußte sich Friedrich II. fast stets eine kräftige und wirksame Partei im Kollegium zu erhalten. Er war bestrebt, dieses für seine Zwecke sogar zu selbständiger, papstfeindlicher Aktion zu drängen, eine oligarchische Umbildung der Kurie herbeizuführen.

Gegen Gregor IX. 1239 und Innocenz IV. $1244{ }^{1}$ ) erinnerte er die Kardinäle daran, daß der Papst bei der ganzen Leitung der Kirche in allen Fragen der Politik und Gesetzgebung an die Mitwirkung des ihm gleich berechtigteu Kardinalskollegs gebunden sei; ihm wies er die Aufgabe zu, ein Konzil gegen den Papst zu berufen.

Zur Verwirklichung eines derartigen, seiner Zeit weit vorauseilenden Gedankens war aber der Kardinalat damals noch nicht reif. Noch wagte er nicht, sich von dem Papstum, in dem die Wurzeln seiner Kraft lagen, zu trennen. Zuden war Friedrich, auf dessen Macht die Kardinäle sich hätten stützen müssen, damals aus der kirchlichen Gemeinschaft ausgestoßen. Sein allerseits bekämpftes und zerbröckelndes Kaisertum konnte ihnen kein genügendes Vertrauen einflößen.

Wenige Jahre zuvor (1234) hatten die Kardinäle vom Papsttum selbst ein dauerndes Machtzugeständnis erhalten, durch Gregor IX. Seine Konstitution ,Rex excelsus' machte jegliche Alienation aus dem Kirchenstaate und aus dem römischen Kirchengute ausdrücklich vom ,commune fratrum consilium et assensus abhängig ${ }^{2}$ ). In erster I Iinie war das. eine Vorbeugungsmaßregel gegen etwaige Neigungen seiner Nachfolger zu Verschleuderungen, zum Sehaden des Kirchenstaates und zur Sehwächung der päpstlichen Macht, besonders zu Gunsten des päpstlichen Nepotismus, der allezeit sich im naturgemäßen Gegensatz zu den Kardinälen, vornehmlich zu den älteren, befunden hat. Gleichzeitig diente die Maßregel, die bereits fixierten Forderungen der Kanonisten entsprach, zur Beruhigung der Kardinalsmajorität, die durch die kaiserfeindliche Politik Gregors IX. eine Gefährdung der päpstlichen Territorialherrschaft befürchtete ${ }^{3}$ ).

1) Bobhmer-Ficker 2427, 2431, 3434 (M. G.. SS. XVI, 364, Const. II, Nr. 215, 252), vgl. Friedr. Graefe, Publizistik in der letzten Epoche K. Friedrichs II. (1909).. $11 \mathrm{ff}, 23,27$.

2) Potthast n. 9368.

s) v. Westenholz, Kardinal Rainer von Viterbo (1912), 43. 
Aus dem folgenden Jahre 1235 liegt der erste urkundlich belegte und anscheinend erfolgreiche Anspruch der Kardinäle ${ }^{1}$ ), die bereits seit dem 12. Jahrhundert eine eigene Finanzverwaltung besaßen, auf die ،Hälfte eines dem Papste zustehenden Census, nämlich des englischen, vor. Um dieselbe Zeit oder nur wenig später dürfte sich die Halbierung auch auf die, servitia communia erstreckt haben ${ }^{2}$ ).

Die langsame, aber sichere Entwicklung ihrer ökonomischen Tendenzen, begründet im Wachsen ihres Ansehens und ihrer Stellung, lieferte den Kardinälen die wirkliche Grundlage für ihre Machtbestrebungen. Da sie einen immer mehr steigenden Einfluß auf die Ergänzung ihres Kollegiums gewannen, konnten sie für eine fortschreitende Reduzierung ihrer Zahl, - was ihnen im 13. Jahrhundert seit dem 'Tode Innocenz' III. im Interesse ihrer Einkünfte und ihrer Machtstellung .zumeist gelang, — und für eine möglichste Verlängerung der Sedisvacanzen sorgen, weil sie da, de facto' allein herrschten und die gesamten Einkünfte des Papsttums bezogen; das häufigere Fintreten der Sedisvakanzen erwirkten sie durch die wiederholte Erhebung zumeist ungefährlicher Greise.

In der allerdings durch Friedrich II. verschuldeten Sedisvakanz von $.12 / 3$. Jahren, vor der Wahl Innocenz IV. (1243), hatten die Kardinäle mehrere Maßregeln über ihre Kompetenz hinaus getroffen, darunter den Widerruf einer Verfügung Gregors IX. mit dem Hinweise, daß bei ihnen ,potestas residet apostolica - sede vacanter 3 ).

Das war ein Eingeständnis über das Ungewöhnliche der Måregel, gewissermaßen eine Entschuldigung, das Bekenntnis des schlechten Gewissens, zugleich aber ein Wiederschein der Schmeicheleien , und lockenden Zugeständnisse, die der Hohenstaufe ihnen früher gemacht hatte. Aus jenem Ausdruck den Beweis etwa dafür folgem zu wollen, daß während der Sedisvakanz die Kardinäle die Vollgewalt des Papstes besitzen, ist. m. E. unangebracht ${ }^{4}$ ).

Innocenz IV. hat sich an die Zusagen der Kardinäle in der Sedisvakanz nicht gehalten, die versprochene Abberufung des Legaten Gregor von Montelongo Friedrich II. abgeschlagen. Er sah die vor der Wahl

1) Th. Ry mer, Foedera, conventiones ... inter reges Angliae et alios, I, 1 (1739), 117. $22^{*} \mathrm{ff}$

2) E. Goller, Die Einnahmen der apost. Kammer unter Johann XXII. (1910),

3) Potthast n. 11075 .

4) Matthaeus Parisiensis, Chronica IV, 250; ebenso haben Deusdedit, Huguccio, Johannes Teutonicus und Bartholomaes von Brescia, später Johannes Monachus behauptet, daB das Kolleg ganz und gar in die Stelle des verstorbenen Papstes einrücke (vgl. Sägmüller a. a. 0. 227). 
gemachten Kardinalsversprechungen für unverbindlich an, das entsprach. der später beliebten Praxis der Päpste bei den Wahlkapitulationen.

Der Kampf des Papsttums gegen die Staufer führte - in seiner: Fortsetzung gegen Manfred - im Konklave des Jahres 1261 zur Wahl eines Franzosen durch die guelfisch gesinnte Majorität der aus der politischen Schulung Innocenz' IV. hervorgegangenen Kardinäle.

Urban IV. leitete eine neue Politik für die Kurie ein: Die Anlehnung an Frankreich durch das Angebot der Krone des sizilischen Stauferreichs, das Innocenz IV. einmal hatte direkt beherrschen wollen ${ }^{1}$ ), an Karl von Anjou, - durch Verstärkung der französischen. Partei im h. Kollegium.

Von den allmählich sich im nationalen Selbstgefühl innerlich konsolidierenden Nationen und Fürsten-Staaten griff jetzt der am meisten gefestigte in die Entwicklung des Papsttums und der allgemeinen Kirche ein, um mit deren Hilfe die eigene Macht zu stärken und zu erweitern, nicht zuletzt in der stillen Hoffnung, seinen Anspruch auf die Erbschaft Karls des Großen, auf das Kaisertum, durchsetzen zu können.

Auf Jahrhunderte hinaus begannen nunmehr Ansprüche und Kämpfe des französischen Königshauses um Sizilien, jenen Unruhenherd für das Papsttum seit den Belehnungen der Normannen durch Nicolaus II. und Hadrian 1V., - begann für das Papsttum selbst eine, wohl zeitweise unterbrochene, doch immer stärker werdende Abhängigkeit rom französischen Königtume. Es hub jenes weltgeschichtliche Drama an, dessen Höhepunkt das Exil in Avignon war, dessen Sehlußakt die Wiederaufrichtung des alleinigen Papsttums im Konzil zu Konstanz werden sollte, - das aber gleichzeitig die politische Konstellation schuf, die der Erhebung des Kardinalats und ihrem Ausdrucke in den Wahlkapitulationen günstig sein sollte.

Vorerst zeigte sich jetzt im Kollegium durch den Gegensatz einer französisch-kirchlichen zu einer italienisch-aristokratischen Partei eine, vom Minoriten Roger Bacon scharf gegeißelte, politische Zerissenheit, die im Verein mit dem unsachlichen Ehrgeiz der einzelnen Purpurträger eine 22/3 Jahre währende Sedisvakanz 1268 nach dem 'Tode Clemens' IV. verschuldete. Glaubten aber die Kardinäle dann in Gregor X. einen gefügigen Papst gefunden $\mathrm{zu}$ baben, so sollte die Enttäuschung nicht lange ausbleiben, wie bei so manchem Papste bis zu Urban VI. herab, der ihrem Kollegium nicht angehört hatte. Wohl erlangten sie von $197 \mathrm{ff}$.

1) C. Rodenberg, Innocenz IV. und das Königreịch Sizilien (1892), 180, 
dem ahnungslosen Neugewählten, bei seiner Ankunft aus dem heiligen Lande, die Überweisung der Hälfte des päpstlichen Census aus Sizilien Sie wußten, trotz seiner späteren Gegenerklärung ${ }^{1}$ ), die Konzession zu einer dauernden zu gestalten, wodurch sie Mitinteressenten auch an der politischen Verwaltung der Insel wurden.

Einschneidend und folgenschwer war der Angriff, den Gregor X. gegen ihr Fundamentalrecht durch seine Konklave-Ordnung ausführte (1274). In der Erbitterung über Macht und Willkür der Kardinäle, wollte der Dominikanergeneral Humbertus de Romanis, der Verfasser einer offiziösen Denkschrift, bei Verzögerung der Wahl ihre Rechte be'schränkt sehen durch die Heranziehung anderer Elemente aus der Kurie. Statt dessen führte Gregor X., anknüpfend an die Vorgänge in mehreren der letzten Vakanzen, durch die Konstitution, ,Ubi periculum ' ${ }^{2}$ ) die Einsperrung, das Konklave, ein. Wohl möglich, daß Humbertus die Einsperrung mit allmähliger Speise-Entziehung ebenfalls empfohlen hatte, weil sie - vermutlich in Nachahmung von Gebräuchen in lombardischen Kommunen ${ }^{3}$ ) - seit 1228 in seinem Orden bei der Wahl des Generals als bewährt erfunden worden war. Auch seinem Vorschlage gemäß, sollten die Kardinäle nunmehr keine Einkünfte des Papstes oder der römischen Kirche in der Vakanz für sich verwenden, keine Geschenke oder Servitien annehmen 4). Sehr wahrscheinlich war Gregor X. darüber unterrichtet, daß der kurz zuvor 1271 verstorbene Kanonist Henricus de Segusia (de Bartholomaeis), der Cardinalis Hostiensis, seinen Kollegen, während des Interstitium, im allgemeinen das Recht, Verfügungen wie der Papst treffen zu dürfen, nur im Falle großer, klar vorliegender und unmittelbar drohender Not zugestanden hatte ${ }^{5}$ ).

Gregor beschränkte dieses Recht auf die notwendige Abwehr einstimmig von allen Kardinälen als dringend erkannter Gefahren zur Verteidigung des Kirchenstates.

Für die Machtstellung des Kardinalats ist es bezeichnend, daß Gregor X. sein Wahldekret nur mit Hilfe der auf dem 14. Konzil zu

1) Albgegeben durch Berengar de Sûry, vgl. Kirsch, Finanzverwaltung des Kardinalkollegiums (1895) S. 3 f., wo der Name unrichtig angegeben ist, und die recht eingehende Untersuchung bei R. Sternfeld, Kard. Joh. Gaetan Orsini (1905), $195 \mathrm{f} ., 321 \mathrm{ff}$.

2) c. 6 , in VIto De elect. I, 6 .

s) Denifle in Archiv I, $215 \mathrm{ff}$., Wenck in Gött. gel. Anz. 1900 S. $166 \mathrm{ff}$.

4) E. Brown, Appendix, pars III, Cap. II; Auszug bei Mansi, Sacrorum Consilium nova et ampl. collectio, XXIV, 130.

5) Apparatus ad c. Cum ex eo $(14, X)$. De poenit. et remise. (V, 38) Potestatis. Vgl. Sägmüller a. a. O. 228, N. 1. 
Lyon 1274 versammelten übrigen Pälateu, vor allem der Bischöfe, durch Überlistung der Kardinäle durchbringen konnte. Sie wußten bald und wiederholt eine Aufhebung des widrigen Papstwahlgesetzes durchzusetzen.

Die Aufhebung und Wiederherstellung war zumeist ein Merkmal für die Selbständigkeit und politische Bedeutung der jeweiligen Päpste, ausgenommen bei dem durch die Konstitution persönlich betroffenen Nicolaus III. Er erkannte ihre Ergänzungsbedürftigkeit bei der barbarischen und parteiischen Handhabung von Seiten Karls von Anjou und der Einwohner Viterbos in den Sedisvakanzen des Jahres 1276. Die gegen die Vorherrschaft eines Fremden gerichtete Konstitution Nicolaus' III. „Fundamenta militantis" über die Senatorenwahl vom 18. Juli 1278 wurde von den Kardinälen mit zum Rüstzeuge ihrer Vorrechte und Privilegien gezählt. Wendungen, wie die-Hervorhebung der Freiheit bei Papstwahlen und Kardinalspromotionen, ferner die Ausdehnung des kardinalizischen Beratungsgebietes auf, quaecumque negotia lassen kardinalizische Mitarbeit vermuten. Nicolaus IIJ. erkennt die Pflichten ùnd Rechte der Kardinäle als geistlicher Gehülfen und Ratgebern an - vom Standpunkt eines absolutistisch gesinnten Papstes schon eine gewisse Machtkonzession.

Er hatte in dem mit sieben Mitgliedern den ärgsten Tiefstand zeigenden Kollegium bereits durch die erste Promotion von neun Kardinälen den Italienern das Übergewicht verschafft: Der römische Adel dehnte seine Macht- und Einflußsphäre in das h. Kolleg wieder stärker aus. Durch jene Konstitution eines Sprossen ihrer Adels-Geschlechter wuchs die Macht der Kardinäle von neuem in den nun folgenden kurzen Pontifikaten. Es gelang den Kardinälen von dem gefügigsten der Greise, die sie damals erhoben, von Nicolaus IV., 1289 die gesetzliche Festlegung des bereits errungenen Anspruchs auf die Hälfte einer größeren Reihe päpstlicher Einkünfte durchzusetzen, - dazu aber auch einen Anteil an den päpstlichen Hoheitsrechten bei der Verwaltung der betreffenden zinspflichtigen Ortschaften und Länder, nämlich einen Anteil an dex Ein- und Absetzung der Rektoren und Kollektoren, - eine Maßregel, die gleichzeitig gegen den päpstlichen Nepotismus gerichtet war. Die Kardinäle hatten einfach die eine Hälfte der Einkünfte, die als ,divisiones consistoriales ihnen zugestanden war, dem Papsttum entwunden und gleich von der Eintreibung an in selbständige Verwaltung genommen. Die stetig fortschreitende Entwicklung dieses Anteils an den. päpstlichen Einkünften hatte ungefähr fünfzig Jahre zuvor begonnen; nach weiteren fünfzig Jahren war sie unter 
Benedikt XII. 1334 abgeschlossen; allein die Zehnten und die Annaten berührte er nicht. -

Was die Kardinäle bis jetzt gegenüber dem Papsttum in ihren Machtbestrebungen erreicht hatten, wird nun unter dem Zusammenstoß mit einer eminenten Papstpersönlichkeit, mit Bonifaz VIII., der den gewaltigen. Versuch machte, den vordringenden Kardinalat in engere Schranken zurückzuweisen, geprüft und geklärt. Der Kampf, der sich an die Namen der Colonna knüpft, weist einen äußeren Anlaß auf, der mit dem Antagonismus zwischen Papst und Kardinalat nichts zu tun hatte; auch er führte auf Sizilien zurück, auf die Bonifaz verräterisch erscheinende Verbindung des Hauses Colonna mit Friedrich II. von Aragonien 1). Begleitet war dieser Kampf von einer geheimen Kardinalsopposition, die sich ihrerseits an eine äußere Macht wandte, welche bereits festen Euß. in der Kurie gefaßt hatte, an Frankreich, das nicht mehr gewillt war, die päpstliche Besteuerung seiner Untertanen gegen das Lebensintoresse des Staates weiter zu dulden 2). Die opponierenden Kardinäle hatten ebenso wie die Familie Colonna Beziehungen zu der damals sich zur Weltstellung emporringenden Pariser Universität und zu' der Sekte der Spiritualen.

Wenn die Kardinäle dem Einflusse des französischen Königs die Möglichkeit gewährten, sich in einer solchen Weise geltend zu machen, daß dadurch der Überfall zu Anagni, die Übersiedlung des Papsttums nach Frankreich vorbereitet war, so haben sie damit diese folgenschwere. Wendung in der Entwicklung des Papsttums, alles Unglüick, das daraus. folgte, verschuldet.

Vollberechtigt sind deshalb die schweren Vorwürfe, welche gegen die Kardinäle 1314 Dante in seinem Sendschreiben an die italienischen Papstwähler in Carpentras erhoben hat. Die Mehrzahl der von ihm in der ,Divina Commedia' genannten Kardinäle hat der Dichter übrigens. in die Hölle versetzt ${ }^{3}$ ).

Bonifaz' VIII. Kampf mit den Colonna hat seinen Niederschlag gefunden in verschiedenen Kundgebungen auf beiden Seiten. Für die Beurteilung der damaligen Stellung des Kardinalats sind sie nur mit Vorsicht zu gebrauchen, da sie, in der Hitze des Kampfes geschrieben, übertreiben. Jedoch sind sie in der späteren Literatur, vorerst in der sich anschließenden, leidenschaftlichen Publizistik benutzt, auf die ich hier leider nicht mehr eingehen kann.

1) Vgl. die von H. Finke festgestellte Konsistorialrede (MG. SS. XXIV, 477 -480) und die Konstitution ,In excelso' (Reg. Bon. VIII. n. 2388. I. 961-967).

2) Vgl. Wenck in Gött. gel. Anz. 1898, S. 236.

s) Finke, Hist. Z. 1910, S. 498. 
Die Colonna sehen eine der Grenzen der päpstlichen Gewalt im Rate der Kardinäle, die der Pontifex als Mitregenten hören müsse. Ihre Forderungen gehen über jene, welche kardinalsfreundliche Kanonisten bis dahin aufgestellt haben, hinaus. Trotzdem zeigen sie keinen Fortschritt in der Entwicklung des Kardinalats. Anf eine Sanktionierung der von ihnen beanspruchten Beratungs- und Mitregierungsrechte, die etwa durch eine päpstliche Dekretale erfolgt wäre, können die Kardinäle nicht hinweisen, - - was zu tun sie nicht verfehlt hätten, wenn solche, zwar unüberliefert, doch existiert hätten. Zugestanden war dem Kollegium das mitentscheidende Konsensrecht nur in den Fällen, die die Konstitutionen Gregors IX. und Nicolaus' IV. festgelegt haben. Von einem wirklichen ,Versuche, dem päpstlichen Absolutismus die aristokratische Oligarchie des Kardinalats entgegenzusetzen, 1) kann bei den Colonna nicht geredet werden. Was sie vorbrachten, waren mit E. nur Theorien zur Verteidigung. Auf eine praktische Verwirklichung dieser Theorien mit Hülfe Philipps des Schönen hätten sie sich erst Hoffnung machen können, wenn der Überfall zu Anagni, sechs Jahre später, wirklichen Erfolg gehabt hätte.

Damals aber, als Bonifaz Absetzung und Privierung der ColonnaKardinäle im Konsistorium vorgenommen hatte, waren sie von Frankreich im Stiche gelassen und von ihren eingeschüchterten Kollegen durch ein Rundschreiben öffentlich bloßgestellt. Schon aus der wörtlichen Übereinstimmung mit Wendungen der Konstitution Bonifaz' VIII., ,Lapis abscissus‘ vom 23. Mai 1297 bei Darstellung der beruflichen Tätigkeit der Kardinäle macht diese Erklärung vom Ende 1297 den Eindruck einer erzwungenen Arbeit, - wo Denifle ein ,objektives' Urteil ${ }^{2}$ ) vermuten zu können meint: Gemeinsame Feier des Sakraments mit dem Papste, Teilnahme an seinen gottesdienstlichen Handlungen, Ratserteilung bei Provisionen und Definitionen der Kirche, sowie, in aliis articulis spiritualibus et temporalibus. Statt dieses allgemeinen Ausdrucks der Kardinäle, der ihre sonstigen Ansprüche umfaßt und umhüllt, nennt der Papst nur noch die Unterzeichnung der von ihm erteilten Privilegien. Seine Entgegnnngen bezeichnen das Mindestmaß der kardinalizischen Rechte.

Bonifaz hatte die Kardinäle von der Teilnahme an politischen Angelegenheiten in der Theorie und in der Praxis ausgeschieden, wie es alle bedeutenderen Päpste getan haben. Er ersuchte die Kardinäle nicht um einen Rat, den er hätte befolgen wollen, sondern er verlangte

1) Wie das R. Scholz, Publizistik zur Zeit Philipps des Schönen (1903) S. 206 annimmt.

2) Archiv f. Literatur- und Kirchengesch. V, 509, 524 ff., 528.

Mitteiluugen $\mathrm{XXXV}$. 
von ihnen Zustimmung zu dem, was er beabsichtigte. Die Gewohnheitsrechte und die finanziellen Errungenschaften des Kollegiums erkannte er vollkommen an. Das Halbierungssystem wurde unter ihm auf weitere Einnahmequellen ausgedehnt und organisiert. Eine geordnete Buchführung in der, camera collegii ist sogar erst unter ihm nachweisbar.

In Anagni, im Zentrum des von Bonifaz gestifteten großen Nepotenreichs, fand der Kampf der Colonnan die wohl erst nach 1300 in engere Verbindung mit König Philipp von Frankreich traten, seinen Abschluß. Nur mit Hilfe Sciarras, ihres mächtigen Hauptes, war der Überfall Nogarets, der Bonifaz nach Frankreich vor das Konzil schleppen wollte, möglich. Die fünf in Anagni anwesenden Kardinäle hielten zum Teil beim überfallenen Papste aus, zum Teil hatten sie fliehen müssen, ohne ihren Besitz vor den Verschwörern schützen zu können. Von einer Opposition des Kardinalats gegen den Papst in Anagni läßt sich trotz der geheimen Sympathien eines Napoleon Orsini und Richard von Siena für Philipps und Nogarets Vorhaben ${ }^{1}$ ), m. E. nicht reden.

Die Ideen und Wünsche der Kardinalsopposition hatte einer ihrer Führer, der französische Kanonist Johannes Monachus, in einer idealisierenden Darstellung der angeblich durch Verjährung erworbenen Gewohnheitsrechte des Kollegiums aus der empfehlenswerten Praxis unter Bonifaz' Nachfolger, dem milden Benedikt XI., zum Ausdruck gebracht, der nach einem aragonesischen Berichterstatter fast nichts ohne Rat der Kardinäle tat. Johannes setzt das Verhältnis des Pontifex zum Kollegium dem des Bischofs zu seinem Domkapitel gleich. Die Rechte in der Sedisvakanz wollte Johannes Monachus vergrößert sehen nach den Argumenten der alten Glossatoren aus dem Beginne des 13. Jahrhundert, jener Theoretiker, die mit langen Sedisvakanzen und mit Übergriffen des Kardinalats noch keine zur Vorsicht mahnenden Erfahrungen gemacht hatten. Aus dem, was Johanns Zeitgenosse, der Kurialist A ugustinus Triumphus, den Kardinälen theoretisch während der Sedisvakanz versagt, - vor allem nämlich in die persönlichen Reservatrechte des Papstes einzugreifen, - geht hervor, was sie, besonders in den häufigen Interregnen der Periode von 1287 bis 1305, trotz der Gegenkonstitution Gregors X. sich anzumaßen versucht hatton, so vor allem z. B. das ihnen von Bonifaz VUI. in der Konstitution gegen die Colonna ,Ad succidendos' (1298) vorenthaltene Recht der Lossprechung

1) R. Holtzman n, Wilh. v. Nogaret (1898), 64, 78, 79. 
von der Exkommunikation, das ihnen ihr Kollege, der Cardinalis Hostiensis, zugestanden hatte.

Unter Benedikt XI. zeigte das Kolleg, befreit von dem lastenden Drucke des gewaltigen Papstes, eine eigenartige Parteikonstellation in Rücksicht auf die neue Theorie von der unbeschränkten Souveränität der staatlichen Gewalt. Von Frankreich her kam der Anlaß des Zwiespalts, und Frankreichs Einfluß sollte das nun folgende, die Zukunft des Papsttums bestimmende Konklave entscheiden.

Der Gascogner Clemens V.. ward durch König Philipp zum vorläufigen Verbleiben in Frankreich bewogen, aus dem ein dauerndes werden sollte. Der vor allem von finanziellen Erwägungen getragenen Spezialpolitik seines Heimatstaates zu Liebe, ließ Clemens es in innerlicher Haltlosigkeit zu, daB das Oberhaupt der Gesamtkirche aus seinem angestammten Sitze herausgerissen wurde. Das Kardinalskolleg, das perennierende Corpus in der Kirchenleitung, war durch drei Kreationen von Clemens in steigendem Maße französiert, — dadurch vom König : für sich gewonnen und an Frankreich gefesselt.

Somit beherrsehte Philipp die kirchliche Oberleitung, deren Umwandlung in ständische Formen er damit also begünstigte, die päpstliche Politik für seine Zwecke, - mochten die einzelnen der in Charakter und Energie verschiedenen Päpste mehr oder weniger gefügig sein, - mochten sie, im verständlichen Drange nach Wiedergewinnung ihrer Selbständigkeit, im geheimen Heinrich VII. begünstigen oder die .Rückkehr nach Italien betreiben, - Franzosen waren sie alle. Vor allem hatte jetzt der französische König die finanziellen Hilfsmittel der Kirche zu seiner Verfügung.

Gleichzeitig erhielt das Kollegium einen selbständigen Rückhalt von a u ßen her. Erst in Frankreich wäre seine Zusammenfassung im nationalen Landesinteresse gegen einen etwa ungefügigen Papst möglich gewesen, erst in Avignon konnte eine Opposition im hl. Kollegium gegen das Oberhaupt der Kirche überhaupt verwirklicht werden, wie sie Kaiser Friedrich II. vergeblich angestrebt hatte.

Mit den Kardinälen und ihrer Stellung beschäftigten sich auf dem Konzil zu Vienne 1311 zwei von Bischöfen verfaßte Schriłten. Die wichtigere von ihnen, die des Wilhelm Durand 1), war von Clemens V., der das Konzil einberufen hatte, selbst angeregt worden. Die Wiederherstellung einer ideal gedachten ursprünglichen Kirchenverfassung -auf der Grundlage des Episkopalismus und Konziliarismus anstrebend, wirft der Bischof den Kardinälen vor allem Simonie und Nepotismus vor,

1) De modo concilii generalis celebrandi; vgl. Scholz a. a. 0. $209 \mathrm{ff}$. 
hält es für ungebührlich, daß ihnen höhere Ehren als Erzbischöfen und Bischöfen erwiesen werden. Nicht wie jene seien sie Nachfolger der Apostel, sondern nur Ministranten und Assistenten beim päpstlichen Gottesdienst, Bəi ungebüibrlicher Länge von Sedisvakanzen denkt er wie Humbertus de Romanis an Ersatzwähler, er aber an Erzbischöfe und. Bischöfe.

Clemens V, beschränkte sich darauf, das den Kardinälen fatalePapstwahlgesetz Gregors X. zu erneuern und zu verschärfen 1 ). Daß abər. ein solches Gesetz trotz alledem durch Umstände und Kombinationen illusorisch werden konnte, zeigte sich in der gleich folgenden zweijährigen papstlosen Zeit. Schuld daran waren die schroffen nationalen Gegensätze im Kollegium, die noch nicht konsolidierte Lige der Kurie in Frankreich, ihre Unfreiheit gegenüber dem Könige von Frankreich. und dem von Neapel, als Territorialherrn von Avignon.

Da die Position des Kollegiums in Frankreich eine andere war, als im Jahrhundert zuvor in Rom, so bemühte es sich auch nicht mehr so sehr um die Beseitigung jener Papstwahlordnung. Denn einerseits. tat sie der Macht des Kollegiums keinen so argen Abbruch mehr, da die ganze Leitung der Sedisvakanz unter Aufsicht des französischen Königs stand; anderseits erhielten die Kardinäle den größeren Teil der päpstlichen Einnahmen während des Interregnums - nachträglich als Geschenk des Neugewählten ${ }^{2}$ ).

Der furchtbare Schaden, den das Eingreifen des französischen Königtums über Kirche und Kardinalat gebracht hatte, bewies die Berechtigung der Rückkehrbestrebungen der italienischen Kardinäle; sie fühlten, außer der verständlichen Heimatssehnsucht, daß das Papsttum, entwurzelt aus Rom, alle Zuversicht in sich, alles Vertrauen der anderen verlieren müsse. Daß Johann XXII. seine Überzeugung von der Berechtigung dieses Strebens notgedrungen vor dem französischen König verheimlichte, trug ihm die heftigste Gegnerschaft der italienischen Kardinäle ein. Johann fürchtete ihren Rückhalt bei dem Adel Roms ${ }^{3}$ ), er rechnete mit der Möglichkeit ihrer Verständigung mit Ludwig dem Baiern und gab deshalb die ersehnte Rückkehr auf. In der Tat knüpfte Ludwig der Baier mit Napoleon Orsini und den italienischen Kardinälen unter Vermittlung der Minoriten im Jahre 1334 Unterhand-

ג) Konstitution ,Ne Romani pontificis‘: c. 2 Clem. 1, 3.

2) Vgl. die Zusammenstellung der Wahlgeschenke bei P. M. Baumgarten, Untersuchungen und Urkunden über die Camera collegii cardinalium (1898) CLIIII ff.

8) Vgl. Lambert Guerrici de Hoyo, Liber de commendatione Johannis XXII. c. 10 (R. Scholz, Unbekannte kirchenpolit. Streitschriften II (1914), S. 163 f.). 
lungen an. Sein Anerbieten an die Kardinäle, ein allgemeines Konzil einzuberufen, ward aber durch den Tod des Papstes gegenstandslos. Jedoch war der Gedanke Friedrichs II. und Philipps des Schönen wieder aufgenommen, die Weltaktion des Kardinalats zu Pisa vorbereitet.

Benedikt XII. mußte dem mächtigen Kardinalat, statt ihm seine anfangs beabsichtigten, wünschenswerten Reformen aufzunötigen, weitere Zugeständnisse machen, außer reichen Wahlgeschenken vor allem das Kontrollrecht bei der Rechnungsablage über die jetzt fast durchweg mit jenem zu teilenden päpstlichen Einkünfte. Er hatte noch auf einen starken Schatz blicken können, der von Clemens V., besonders von Johann XXII. durch die systematische Ausgestaltung der Annaten und der Kanzleitaxe, durch die Erweiterung der päpstlichen Reservationen, trotz der Einnahmeausfälle in Avignon, angehäuft worden war. Anders wurde es aber unter Clemens VI.! Dem schon an sich verschwenderischen Papste ward die kostspielige Unterstützung Frankreichs in dessen Krieg gegen England aufgedrängt, die ihn in finanzielle Verlegenheit bringen mußte.

Mit einer Anleihe von 1600 Goldgulden trat im Dezember 1350 Clemens VI. und damit zum ersten Male das Papsttum in eine finanzielle Abhängigkeit vom mächtigen Kardinalskolleg. Es war zu erwarten, daß es in seiner damaligen unkirchlichen Verfassung sich aus der Finanzangelegenheit einen Machtzuwachs herausgestalten würde. Durch einen neuen Zwangsweg, durch eine Wahlkapitulation, wie solche in deutschen Klosterkonventen und Domkapiteln ausgebildet waren auf die Parallele war kurz zuvor von Kardinal Johannes Monachus, von Wilhelm von 0 ccam und jüngst noch vom Lütticher Kanonikus Johannes Hocsem hingewiesen worden - versuchten die Kardinäle ihre Ansprüche dem Oberbaupte aufzuoktroyieren.

Vor einer Schwächung des Papsttums hatten sich die Kardinäle bis dahin im großen und ganzen gehütet. Denn auf seine Kraft stiitzte sich ihre Macht. Aber kurzsichtig und von persönlichem Egoismus verblendet, glaubten jetzt die zumeist französischen Kardinäle, zwischen denen gerade damals die scharfen Parteigegensätze nachgelassen hatten, eine andere und offensichtig kräftigere Stïtze im Landeskönigtum zu besitzen, gegen das Papsttum, dessen internationaler Charakter jetzt bedenklich gemindert war. Es bildete nunmehr gewissermaßen nur die höchste Staffel in der französischen Hierarchie. Dem in dieser Hinsicht im Werte gesunkenen Papsttum ${ }^{1)}$ gegenüber zeigte die Macht des Kardinalats in A vignon eine relative Steigerung.

1) Mit dieser Ansicht, gegen die sich in der Diskussion ein Einwand von Seiten F. Vigener's erhob, stimme ich den Ergebnissen von J. Haller, Papsttum 
Die Wahlkapitulation betraf naturgemäß die Sicherstellung dereigenen Position, des Bestandes und der Privilegien des Kollegiums, die Bestätigung und selbstverständliche Erweiterung der schon erlangtẹn päpstlichen Konzessionen Gregors IX. und Nicolaus' IV., sowie des Gewohnheitsrechtes der Teilnahme bei Ergänzung ihres Kollegiums, das unter Benedikt XII. der Kardinal Jacob Gastani Stefaneschi im ,Ordo Romanus vermutlich auf Veranlassung der Kardinäle festgelegt hatte. Andere Bestimmungen richteten sich gegen den verhaßten päpstlichen Nepotismus, andere sollten ihnen das Recht der freien Meinung im Konsistorium, eine Ausdehnung des Beratungsgebietes dort sichern.

Größtenteils sind die Artikel der Kapitulation direkt oder indirekt fiuanzieller Natur, begründet in der ökonomischen Verschlechterung des Kardinalats zu Avignon; sie konnte auch durch die vielgeschmähte Pfründenanhäufung bei den eịzalnen Kardinälen nicht vollständig gehoben werden. Bezeichnender Weise ist von einer Mitwirkung bei "causae arduae", von einer Festlegung der umstrittenen Rechte in der Sedisvakanz keine Rede.

Schon die relative Mäßigung in den Forderungen, gewisse Wendungen des Dokuments und die Tatsache, daß es sämtliche Errungenschaften der Kardinäle zusammenfaßt, lassen erkennen, daß diese Kapitulation die erste päpstliche war. Der rechtskundige Eugen d'A lbert, der als Innocenz VI. 1352 aus der Wahl hervorging, hob sie auf, unter Berufung auf die päpstliche ,Plenitudo potestatis' und auf die Papstwahlkonstitution Gregors $X$. Sein Protest richtete sich vor ailem gegen die Form, gegen die Existenz des Dokuments, gegen das noch nie dagewesene Unterfangen. Sein scharfes Verbot gegen die Aufstellung derartiger Kapitulationen wirkte nach! Erst nach vier Jahrzehnten und unter ganz anderen Verhältnissen haben die Kardinäle auf diesen mißglückten ersten Versuch zurückgegriffen, auf diese Kraftprobe, der ein Vierteljahrhundert später eine weit stärkere folgen sollte, als nämlich Papst und Kardinäle die Kurie nach Rom in den mit völligem Abfall drohenden Kirchenstaat hatten zurückverlegen müssen und somit zugleich, unterstützt durch die antifranzösische Politik Kaiser Karls IV., den Traum der meisten avignoneșischen Päpste und damaligen italienischen Kardinäle verwirklicht hatten.

und Kirchenreform I (1903), 206 ff. bei. Die damalige Schwächung des Papsttums hat $\mathbf{m}$. E. die durch Prof. K. Wenck in Marburg angeregte Dissertation von Erich Schelenz, Studien zur Geschichte des Kardinalats im 13. und 14. Jahrhundert, (1913) nicht gentigend berücksichtigt. - Eine Minderung der ,tatsächlichen Bedeutung des Kollegiums in Avignon nimmt Wenck in: Religion in Gesch. und Gegenwart III (1912) Sp. 930 an. 
Da starb 1378 in Rom Gregor XI. Sein Nachfolger war ein Italiener, Urban VI. Sittenstreng, aber leidenschaftlich und undiplomatisch, bedrohte er die verwöhnten französischen Kardinäle mit Reformen, mit einem Pairsschub italienischer Nationalität, der ihre Stellung und ihren Einfluß untergraben hätte, - vor allem versagte er ihnen die Rückkehr in die französische Heimat. Damit trat er aber zugleich den politischen Wünschen des mächtigen Frankreich entgegen!

Im Gefühl, dem von ihnen erhobenen Nichtkardinal gegenïber dem letzten dieser Art - Träger der Tradition des Papsttums zu sein und einer zwar geheimen, aber treibenden Förderung durch Frankreich sicher, hielten sich die Kardinäle, ein Vierteljahrhundert nach dem ersten Wahlkapitulations-Versuch, für stark genug zu einer offenbaren Revolution, nämlich die nach ihren eigenen Erklärungen rechtmäßige Wahl eines Papstes nachträglich (äußerlicher Vorwände wegen) für ungültig zu erklären, - ihn also abzusetzen, ohne Rücksicht auf eventuellen Wert und Würdigkeit seiner Person für die Gesamtkirche - nur weil sie sich in ihren egoistischen Voraussetzungen verrechnet hatten 1 ).

Als ein Konzilsprojekt dreier neutraler Kollegen, das ihnen vom Rechtsstandpunkt weder geboten, noch überhaupt erlaubt erschien, an der Ortsfrage gescheitert war ${ }^{2}$ ), beanspruchten die Kardinäle die Entscheidung über die Gültigkeit der Papstwahl für sich als alleinige Schiedsrichter über das Papsttum.

Dieser Standpunkt der Überhebung der Kardinäle, der von Kanonisten aus ihrer Mitte und Ungebung vertreten und verteidigt worden ist, bezeichnet m.E. den absoluten Höbepunkt in der Selbstbewußtseins-Entwicklung des Kardinalats.

Die Auffassung, daß die Universalkirche, da sie denjenigen als Papst annehme, den die Kardinäle gewählt haben, demgemäB den zu verwerfen habe, den die Kardinäle verwerfen, unterschätzte die internationale Bedeutung des Papsttums, überspannte hingegen, in Selbsttäuschung über die gegebenen Machtverhältnisse, die Stellung des Kardinalats.

Die weittragende, folgenschwere Bedeutung erhielt der Schritt erst, als die französischen Kardinäle den notwendigen staatlichen Rückhalt gefunden hatten, naturgemäß im französischen Königtum. Im englischen Kriege gedemütigt, hatte es die Verlegung der Kurie nach Rom,

1) Vgl: Breflau's Einwand im Bericht über die XIII. Versammlung deutscher Historiker in Wien S. 25 .

2) Nach Kard. Petrus Flandrin (vgl. Fr. Bliemetzrieder, Literar. Polemik zu Beginn des Gr. Abendländischen Schismas, 1910, \$. 63 f., 94* f.). 
die zudem nur als vorübergehend gedacht war, nicht hindern können. Jetzt benutzte König Karl V. die dargebotene Kombination, Papsttum und Kurie mit ihren Finanzquellen wieder in Frankreich festzulegen. Wobl hatte eine Pariser Nationalsynode im September 1378 die Kardinäle an den Richterspruch eines Generalkonzils verwiesen. Aber ehe die Kunda davon den Kardinälen übermittelt war, hatten sie bereits, ermutigt vom Könige, allerdings ohne den zähen Widerstand des im Stich gelassenen Urban VI. vorauszuahnen, den Kardinal Robert von Genf, der Beziehungen zum französischen Königshause besaß, zum angeblich rechtmäßigen Papst als Clemens VII. erhoben.

Trotz des Widerwillens der Kardinäle trat die Konzilsidee in der Publizistik mehr und mehr in den Vordergrund, anknüpfend an litərarische Vorkämpfer in den antipäpstlichen Streitigkeiten Philipps des Schönen und Ludwigs des Baiern, besonders an Johannes von Paris und Wilhelm von Occam, ferner an Thomas von Aquino und an gelegentliche Äußerungen von Huguccio und anderen. Auf Grund der aristotelischen Notstandslehre ward die Notwendigkeit des Konzils ohne päpstliche Berufung durch die Deutschen Heinrich von Langenstein und Konrad von Gelnhausen dargelegt; beide waren Professoren an der Pariser Universität, die, im Interesse ihrer universalen Stellung und der finanziellen Lage ihrer Mitglieder, der Einheit des Papsttums und der Kirche bedurfte.

Sehr bald jedoch trat in den kirchlich-politischen Erörterungen der seheinbar einfachere Vorschlag in den Vordergrund, daß beide Prätendenten zedieren sollten. Diesen Vorschlag empfahl die Pariser Universität am 6. Juni 1394 dem inzwischen zum Thron gelangten, häufig gemütskranken König Karl VI. Sie ließ ihn aber gleichzeitig auch Clemens VII. und dem Kardinalskolleg zugehen, letzterem noch mit der Drohung, daß, falls es etwa versagen sollte, das heilige Unionswerk, zum Nachteil der Kardinäle von der weltlichen Macht, d. h. vom französischen Königtum, in die Hand genommen werden würde ${ }^{1}$ ).

Diese Drohung erklärt die nun folgenden Maßregeln der Kardinäle bei dem bald darauf eintretenden Tode des Papstes (16. September 1394), nämlich die Mißachtung der Aufforderung des Königs, von dem sie doch in Wahrheit abhängig waren, mit dem Wahlgeschäft zu warten, ind die Aufstellung einer Wahlkapitulation im Sinne des empfohlenen Zessionsmodus. Sie machte dem zukünftigen Papst die Beendigung des Schismas zur Pflicht, a ber unter Oberleitung des Kollegiums. Die Kardinäle hatten sich unter dem Namen „Papst' nur ein scheinbares Ober-

1) Boulay, Historia universitatis Parisiensis, IV (1668), $700 \mathrm{f}$. 
haupt geben wollen. Es sollte ausführendes Organ ihrer Unionsmaßregeln, Vertreter ihrer eigenen Interessen bei der zu erwartenden Union, aber nicht Inhaber der absoluten Machtvollkommenheit sein.

Die Kardinäle meinten, die Unionsangelegenheit allein durchführen zu lö̈nnen; sie fühlten sich als Herren der Situation gegenüber dem Könige von Frankreich und gegenüber dem Papsttum. Formell einfach den Verzicht des Papstes, das Ende seiner Würde in Aussicht zu nehmen, hat keine der späteren, nachschismatischen Wahlkapitulationen gewagt. Nur während des großen Schismas erschien der Papst in derartiger Abhängigkeit von seinen Kardinälen!

Der Gewählte, Peter de Luna, als Papst Benedict XIII., wollte an Stelle der Zession, bei der er alles zu verlieren hatte, die, via conventionis' setzen, in der festen Überzeugung, daß bei einer Zusammenkunft mit dem anderen Prätendenten er als der allein wahre Papst hervorgehen würde.

In dem Kampfe, der sich nun zwischen Benedict einerseits, dem französischen Königtum und der Pariser Universität anderseits entspann, standen natürlich die in ihren Hoffnungen auf die Zession getäuschten Kardinäle in der Mehrzahl auf Seiten des französischen Königshauses. Achtzehn von 23 Kardinälen schlossen sich im Jahre 1398 der soeben erfolgten französischen Obedienzentziehung an und verließen den in seiner Burg zu Avignon eingeschlossenen Papst. Drei aus ihrer Mitte entsandten sie auf Einladung des Hofes zur IV. Pariser Nationalsynode im Januar 1399. Aber diese lehnte alle Vorschläge der Kardinäle auf ein Generalkonzil zur Durchführung der Substraktion in beiden Obedienzen, auf Erhaltung, ja womöglich Erweiterung ihrer finanziellen Vorrechte ab.

Das bewirkte in den Kardinälen eine gründliche Ernüchterung, eine innere Abwendung von der französischen Politik, die durch ibre nur teilweise angenommene Substraktion unhaltbare ökonomische und kirchliche Zustände verschuldet hatte. Allerdings waren bei den Vorbereitungen zur Substraktion mehrere Kardinäle beteiligt gewesen.

Zu der Instruktion ${ }^{1}$ ), die jenen drei 1399 abgeordneten Kardinälen mitgegeben war, steht im merklichen Gegensatz ${ }^{2}$ ) der Inhalt einer nach der Synode dem königlichen Rate Ende November 1400 vorgetragenen Rede und ein Traktat, beide vom Kardinal Malesec. Da ist nicht mehr die Rede von einem Generalkonzil beider Obedienzen ${ }^{3}$ ), zu dem die Hilfe des französischen Königs nötig wäre, sondern als Vorbereitung

1) Ehrle in Archiv f. Literatur- und Kirchengesch. VI, $294 \mathrm{ff}$.

2) Martène-Durand, Thesaurus nov. anecdot. II, 1226 sq. und 1193 sq.

3) Dieser Gegensatz ist von Fr. Bliemetzrieder, D. Generalkonzil im abendländ. Schisma (1904), $160 \mathrm{ff}$. nicht scharf genug hervorgehoben worden. 
zu einem solchen, ein Generalkonzil der Obedienz, bei dem die Kardinäle ohne die französische Regierung meinten fertig werden zu können. Die Rückkehr der Kardinäle zu Benedict erscheint bereits im Bereiche der Möglichkeit.

Zweieinhalb Jahre später war sie Wirklichkeit geworden. Aber mit der selbständigen Stellung der Kardinäle gegenüber dem in seine Rechte wieder eingesetzten autokratischen Papst war es vorbei! Die Bestimmung des Vertrags vom 29. März 1403 zu Château-Renard ${ }^{1)}$ zwischen den Kardinälen, den Bürgern von Avignon und dem freigewordenen Papste, als sich Kardinäle und Papst zum ersten Male wie zwei feindliche Mächte Vertrag schließend gegenüberstanden, ergeben die ungünstige Lage der Kardinäle. Si e versprechen unter Eid Benedict in allem Gehorsam, sowie die Betreibung der Rücknahme der Substraktion beim französischen Hofe.

Benedikt hingegen beschränkt sich darauf, die Abhaltung eines: Konzils binnen Jahresfrist, die Bestätigung der Anordnungen der Kardinäle in Aussicht zu stellen, sie seines guten Willens betreffs der reservierten Dignitäten und Benefizien in den substrahierten Gebieten zu versichern, in Konsistorialangelegenheiten nach gew ohntem Gebrauch mit ihrem Rate vorzugehen. Den Eid lehnte er aber ab. Das in Aussicht genommene Konzil unterblieb. Der Versuch der avignonesischen Kardinäle, mit Hilfe einer Wahlkapitulation das Schisma aus der Welt zu schaffen, war also endgiltig mißglückt.

Nicht anders erging es dem römischen Kollegium, das seinen Ursprung erst aus den Kreationen des gewalttätigen Urban VI. herleiten konnte. Seine Kapitulationen vor der Wahl Innocenz' VII. 1404 und vor der Wahl Gregors XII. 1406, beide aufgesetzt in gleich vager Hoffnung, die zum Abfall von Benedikt bereite Gegenobedienz zu gewinnen, blieben gleich erfolglos. Die Wahlkapitulation von 1406 enthielt ein festes Unionsprogramm des Inhalts, daß der Papst zedieren müsse, sobald der Gegenpapst das Gleiche täte oder stürbe, wie es Benedict 1399 gelobt hatte. Der Gewählte sollte nur ein Bevollmächtigter der Kardinäle sein.

Aber ein Fortschritt! Das römische Kollegium nimmt die Verbindung mit dem avignonesischen in Aussicht zur Herstellung einer unanfechtbaren Wahl. Es zieht ferner die politische Öffentlichkeit heran als Garanten dieses Vertrages zwischen Kardinälen und Papst. Es macht sein Vorgeben zur internationalen Staatsaktion. Der Gewählte hatte seine Bereitwilligkeit zur Zession und zur Erfüllung der anderen

1) Archiv f. Literatur- und Kirchengesch. V, 392, $449 \mathrm{ff}$. 
Kapitulationsbestimmungen den weltlichen Herrschern, Korporationen u.s.w. nach dem Dafürhalten der Kardinäle formell anzuzeigen.

Ein Generalkonzil haben die Kardinäle damals nicht in Aussicht genommen, trotzdem der Gedanke durch die wenigstens ,vorgegebene Absicht Innocenz' VII. in Rom geläufig geworden war. Sie waren von der Wirkung ihrer eingehenden und neuen Vorbeugungsmaßregeln fest. überzeugt, wieder in einem Selbstbewußtsein, das wie auch sonst ihren tatsächlichen Machtverhältnissen nicht entsprach.

Selbst als Gregor XII. sich immer mehr ihrem Einflusse entzog, suchten die Kardinäle, ihn durch Zugeständnisse zu gewinnen. Ohne ihn zu der nach Savona vereinbarten Zusammenkunft allein zu gehen, dazu haben sie sich nicht entschließen können, trotz der Gutachten der Rechtsgelehrten Bolognas, die ihr Mitkardinal Balthasar Cossa, Gregors. grimmigster Gegner, veranlaßt hatte. Die Kardinäle willigten zu einer Ausstattung der päpstlichen Nepoten mit Gebietsteilen des Kirchenstaates ein, für den erhofften Preis der zugesagten Zession Gregors 1). Aber alles war umsonst!

Stärker als seine Umgebung wirkte auf den greisen Papst Ladislaus von Durazzo durch seine Umtriebe ein. Von Bonifaz IX. mit dem Königreich Neapel belehnt, benötigte er eines schwachen Papsttums in Mittelitalien und darum der Fortdauer des Schismas, um sich in seinem Besitze zu behaupten und ihn möglichst über ganz Italien ausdehnen zu können. Durch seine Kriegszüge und seine Gegenintriguen wußte er, wie einst Innocenz VII., jetzt Gregor XII. und die Kardinäle in steter Besorgnis und Unruhe zu erhalten.

Frankreich hingegen wollte sich Neapel für die Anjou sichern, um von hier aus das Papsttum beherrschen zu können. Gewann es. auch das römische Kollegium für sich, dann war die Wahl eines von ihm abhängigen Papstes gesichert, gleichzeitig die Hoffnung auf Wiedererlangung der kirchlichen Finanzquellen eröffnet ${ }^{2}$ ).

Den Gesandten Frankreichs, welche im Frühjahr und Sommer 1407 an den Kurien Benedicts und Gregors mit deren Kardinälen, sowie sonst in Italien, geheime Unterhandlungen angeknüpft hațten, gelang es. zusammen mit den Boten der Pariser Universität, die Katastrophe vorzubereiten. Sie brach in Paris im Mai 1408 gegen Benedict mit der Proklamierung der gallikanischen Freiheiten und der Neutralitätserklärung der französischen Kirche, d. h. der erneuten Obedienzentziehung; aus und wies gleichzeitig eine parallele Entwicklung im Kollegium

1) Vgl. J. Haller in Gött. gel. Anz. 1900 S. 890 f.

2) Die anders lautende Auffassung Valois' von der selbstlosen, zumeist rein kirchlichen Rolle Frankreichs ist das Resultat seines starken Nationalgefühls. 
Gregors auf. Eine Kardinalskreation, entgegen den Wahlkapiteln Gregors, gab dort fast gleichzeitig den Anlaß zur Flucht der Kardinäle von Lucca, dem damaligen Sitze der Kurie, nach Pisa, wo ihnen die Republik Florenz ein Asyl angeboten hatte. Sie traten in Livorno in Unterhandlung mit den Gegenkardinälen, zuerst aucb noch mit Benedict; er mußte aber bald in seine spanische Heimat fliehen.

Die Vereinigung der beiden Kollegien war freigegeben. Der in den Wahlkapitulationen vorgesehene Fall verwirklicht, der Wille Frankreichs erfüllt!

Die Kardinäle sollten nun weiter und vollkommener als zuvor die Werkzeuge seiner kirchlichen und italienischen Politik sein!

Wie im Jahre 1378 Urban VI. von seinem Kollegium verlassen worden war, so 1408 Gregor XII. und Benedict XIII. von den ihrigen. Aber von der Überhebung, daß die Kardinäle allein über die Rechtmäßigkeit eines Papstes, über die Streitfrage des Schismas ohne Konzil zu entscheiden hätten, waren sie doch in den dreißig harten Lehrjahren des Schismas abgekommen, die ihnen selbst, sowie dem Papsttum, so starke Schädigungen an Ansehen und in finanzieller Hinsicht gebracht hatten.

Das Ergebnis der Kardinals-Unterhandlungen in Livorno, auf französischem Gebiete, war die Proklamierung des Generalkonzils, falls flie Prätendenten nach dem Inhalte ihrer Wahlkapitulationen nicht zedieren würden, wus ja nicht zu erwarten war (29. Juni 1408).

Unter französischer Ägide, wie die Namen der Zeugen beweisen, war die Verbindung der beiden Kollegien zustande gekommen, jedoch nur äußerlich und lose. Während des Konstanzer Konzils ist ihr Nationalitätengegensatz am deutlichsten zutage getreten. Vor allem war die Stellung der beiden Kollegien zu ihrem Oberhaupte keineswegs die gleiche. Gereizt durch die Ausflüchte Gregors, durch die Nutzlosigkeit -der ihm gewährten Zugeständnisse, zeigten sich seine Kardinäle allen seinen Anerbietungen und von weltlichen Staaten unterstiutzten Vermittlungsversuchen gegenüber völlig unzugänglich.

Die avignonesischen Kardinäle hatten Benedikt die Obedienz noch nicht einmal bei den ersten Verhandlungen im Konzil zu Pisa aufgesagt. Nach den Erfahrungen bei der ersten Substraktion setzten sie in Frankreich kein Vertrauen mehr.

Jetzt war die Frage zur Beantwortung in der Praxis reif: Können die Kardinäle ein Generalkonzil einberufen, nachdem sich gemäß seinem Ursprung aus der römischen Gemeindeversammlung ${ }^{1)}$ und auf Grund

1) Sohm, Kirchenrecht I, 448. 
der pseudo-isidorischen Dekretalen die kirchliche Lehre ausgebiddet hatte, daß die Berufung nur dem Papste als ein jus essentiale zustehe, wobei an den Fall eines Schismas nicht gedacht war?

Wäre ihnen dieses Berufungsrecht wirklich und gesetzmäßig zugestanden worden, dann kätten die ehemaligen Sakramentspriester der Stadt Rom die höchste Staffel auf der Bahn ibrer Machtbestrebungen erstiegen.

Alle Gutachten und Traktate kardinalsfreundlicher Kanonisten, die. damals dieses Recht aus den Wahlkapitulationen herausinterpretierten, hatten nur einen beschränkten Wert ${ }^{1}$ ). Sie sollten in gewissen Kreisen Stimmung machen für die Absichten der Kardinäle und der hinter ihnen stehenden Machthaber, $\mathrm{Da}$ die Kardinäle selbst nicht von jenen Deduktionen überzeugt waren, beweisen ihre dringenden Wünsche und wiederholten Bitten an Benedict ${ }^{2}$ ), auf dem Konzil zu erscheinen, seiner Berufung zuzustimmen. Sie fühlten, daß sie zur Unạfechtbarkeit des Konzils der Anwesenheit eines Papstes nicht entraten konnten.

Über seine Beteiligung am Konzil der Kardinäle, am Unternehmen Frankreichs, sollte sich nun ein Hauptmachtfaktor entscheiden, der römische König Ruprecht, und zwar auf dem Tage zu Frankfurt im Januar 1409. Aber dort wurde den Kardinälen eine unheilvolle Stimmung vorbereitet durch eine Gegenschrift gegen ihre Konzilsausschreiben, durch die sogenaunten Postillen, die scharfsichtig und rücksichtslos: die Umtriebe der französischen Politik aufdeckten ${ }^{3}$ ). Trotz der Anwesenheit französischer Gesandter entschied sich die Tagung für dieNeutralität statt für die gewünschte Substraktion. Ruprecht selbst verblieb im Treueide bei Gregor.

Mit dieser Entscheidung des damaligen Hauptes des deutschen Reiches, des Inhabers der Imperiums-Tradition, war bereits im voraus. das Schicksal des Pisaner Konzils besiegelt, die Hauptbedingung des Erfolges, die allgemeine Anerkennung der Hauptmachtfaktoren, ihm ver-. sagt. Dem entsprach der Verlauf des Konzils, das von März bis August. 1409 tagte. Den Vorsitz führte das vereinigte Kolleg der 18 Kardinäle, zwischen denen Simon Cramand, der ideelle Urheber des Konzils, als

1) Anderer Ansicht sind M. Souchon, Die Papstwahlen in der Zeit des großen Schismas I (1898), 147 und Fr. Bliemetzrieder, Das Generalkonzil im großen abendländ. Schisma (1904), $243 \mathrm{ff}$, $286 \mathrm{f}$,

2) J. D. Mansi, Sacrorum conciliorum nova et amplissima collectio XXVI, 1131 sq.

s) DRTA. VI, $400 \mathrm{fl}$. - Eine andere Beurteilung der Postillen bei Bliemetzried e r, Generalkonzil $286 \mathrm{ff}$. 
Patriarch und Gesandter Frankreichs, seinen Platz hatte. Die Erklärungen der Gesandten König Ruprechts und die wenig überzeugende Erwiderung durch den Kanonisten Peter Ancaranus blieben ergebnislos. Erst durch besonderen Konzilsbeschluß mußte die Vereinigung der beiden Kollegien und ihre Konzilsberufung, das Konzil selbst als kompetenter höchster Richter in Sachen des Schismas nachträglich sanktioniert werden. Das Siegesbewußtsein der Kardinäle nach Verkündigung der Absetzungssentenz gegen die Papstprätententen und nach Durchsetzung ihres alleinigen Papswahlrechtes, das Drängen des berrschsüchtigen Balthasar Cossa riß sie zu der großen Unklugheit hin, jegliches Entgegenkommen den Gesandten Benedikts, die mit ausgedehnten Vollmachten erschienen waren, und den weitgehenden Anerbietungen der aragonesischen Gesandten zu versagen, verschuldete die.Übereilung der Wahl und damit deren Erfolglosigkeit. Unterhandlungen mit den Prätendenten hätten ihnen sehr wahrscheinlich den fast vollständigen Rest der Anhänger jener zugefübrt.

Die Erhebung des greisen Griechen Peter Philargi als Alexander V. war - vom Standpunkte der legalen Entwicklung des Papsttums - auf revolutionärem Wege erfolgt.

Eine der ersten Pontifikatshandlungen des Neugewählten war die Legalisierung der Vorgänge und der Maßnahmen der Kardinäle, welche zu seiner Erhebung geführt hatten, kraft der ihm nun gewordenen päpstlichen Machtvollkommenheit. Deutlicher konnten Papst, Kardinalat und Konzil das juristisch Bedenkliche in ihrem Vorgehen, die eigene, selbst empfundene Unsicherheit der Welt nicht darlegen.

Wenn die Kirche Alexander V. und seinen Nachfolger als Päpste zählt, während das Pisanum nicht als Konzil gilt, so ist das eine Inkonsequenz, eine Folge der Verwirrung, welche das Schisma auch in -den Rechtsbegriffen angerichtet hatte.

Das Pisanum hatte seine Aufgabe, der Christenheit die Einheit wiederzugeben, ebensowenig erfüllt, wie die Hoffnungen auf eine kirchliche Reformation, deren Ausführung die Kardinäle noch in einer Wablkapitulation versprochen hatten. Die höchste Kraftanstrengung des Kardinalats, die politischen Machinationen Frankreichs waren mißglückt: Statt zweier Päpste gab es deren drei.

Die von den Kardinälen ungelöste Aufgabe übernahm jetzt der ,advocatus et defensor ecclesiae, der neue Träger der Imperiums-Tradition nach Ruprechts Tode, König Sigismund von Ungarn, hier bis zu einem gewissen Maße der Erbe der wenig kardinalsfreundlichen Politik Ruprechts. 
Sigismund war sich wohl bewaßt, daß zum sicheren Gedeihen seines Konzilsplanes die Sanktionierung durch einen Papst nötig wäre.

Eine glüekliche Kombination zwang Alexanders V. Nachfolger, Johann XXIII., auf Sigismunds Plan einzugehen, das Konzil nach Konstanz einzuberufen. Aber durch den plötzlichen Tod des treulosen Ladislaus aus der Notlage befreit, beabsichtigte Johann, durch einen Zug nach Rom sich der Erfüllung seiner Znsage zu entziehen. Daran ward er jedoch von seinen Kardinälen gehindert ${ }^{1}$ ).

Daß also Sigismunds Konzilsunternehmen überhaupt zustande gekommen ist, war Verdienst des Kardinalskollegs. Und es war für das endliche Gelingen der Union nicht sein einziges Verdienst. Es hatte, trotz seines Mißerfolges zu Pisa, seinem Papste die bei weitem größte Obedienz mitgeben können, die nun dem neuen Konzil und seinem Urheber Sigismund in wirksamster Weise zugute kam.

Das Kollegium war damals in seiner Bedeutung g eh ob en worden, es hatte den Stempel reichster Intelligenz erhalten durch Johanns XXIII. Kreatiouen von geistig hervorragenden Persönlichkeiten, erprobten Vorkämpfern für die Union, wie Ailli, Fillastre, Zabarella, Simon Cramaud, teilweise zu Johanns eigenem Schaden. Ganz andere Persönlichkeiten als die verweichlichten Kardinäle der späteren avignonesischen Periode, die wohl gebettet im Milieu der französischen Heimat, wo möglich, dem Papsttum gegenüber Machtterrain abzugewinnen suchten; hatten diese diplomatisch gewandten Männer den Kampf ums Dasein ihrer Institution in den Stürmen des Konstanzer Konzils durchzufechten gegen ihre geistlichen Rivalen, die in nationalen Verbänden fest organisiert waren, und gegen den deutschen König. Ihnen gelang es, die Kräfte des wieder durch die Nationalitätengegensätze gespaltenen Kollegs in einheitlicher Politik gegen die erbitterten Angriffə zusammenzufassen und wirklich zum Siege zu führen.

Durch die Bildung eines ständigen Generalaussehusses isoliert, suchten die Kardinäle, sich um ihren Pontifex scharend, ihre Stützen an den Gesandten der französischen Regierung und des Herzogs von Burgund. Schon hofften sie mit deren Hilfe Herren des Konzils zu werden, seine Verlegung in eine ihnen günstige Interessensphäre aus der germanischen nach Frankreich - durchzusetzen, da stürzte sie die falsch berechnete Flucht ihres Papstes von der erträumten Höhe herab, aber nicht auf die Dauer.

In den Sedisvakanzen des Schismas hatten die Kardinäle trotz .dringender Warnungen Neuwahlen vorgenommen, weil sie in den

1) Tagebuch des Kardinals Fillastre bei Finke, Acta concilii I, 184. 
schwierigen Situationen nicht ohne das Haupt sein wollten, dem mindestens äußerlich die päpstliche Vollgewalt zukam. Die Richtigkeit dieser Erwägung zeigte sich jetzt! Der eigenen Kraft entbehrend, tritt die in der Entstehung und Entwicklung begründete Schwäche des Kardinalats klar und deutlich zu Tage. Sie wird benutzt zu scharfen, aus lang verhaltenem Grimm geborenen Angriffen, zu radikalen Reformvorschlägen gegen die Kardinäle als Urheber der Schismanot, als die. praepotentesten Pfründenjäger.

Die gemeinsame Gefahr hielt die zu zerfallen drohende Institution zusammen. Die Angriffe und Erschwerungen, die den Kardinälen bereitet werden, verfangen nicht auf die Dauer. Den endgiltigen Siegerringen die Kardinäle für ihre Stellung überhaupt, für ihre ganze Zukunft in dem großen Prioritätsstreit, in der Durchsetzung der Papstwahl vor Vornahme der Reformen. Was sie von der allseitig verlangten Reform, die ihnen nur schädlich und gefahrvoll sein konnte, die ihre Macht gebrochen hätte, zugestehen mußten, die Reform ,in capite et curia ergab nur ein geringfügiges Resultat, bewies aber, daß die Kardinäle, unbeirrt in ihrem Zielbewußtsein, für die Konsolidierung ihrer Position jetzt v or der Neuwahl, ausreichend Sorge getragen hatten durch Festlegung einer geringen Mitgliederzahl, als Maximum 24 im Kollegium, und ihrer stärkeren Mitwirkung bei Neukreationen 1). Daß. die Zusammensetzung des Kollegiums eine möglichst internationale sein sollte, um dem Papsttum die politische Unabhängigkeit wiederzugeben, entsprach ebenso den persönlichen Interessen der damaligen Kardinäle, wie dem rein kirchlichen Standpunkte.

Hingegen war den egoistischen Machttendenzen des Kardinalats, im Sinne der ständischen Bestrebungen jener Periode des Korporationswesens, entsprungen der nunmehr erstmalige Versuch, - den zum Kardinalat gehörigen Kanonisten, wie Zabarella und Ailli vorbereitet hatten, nämlich im 1. Reformatorium die konstitutionelle Mitrıgierung des Kollegiums durch eine ,Professio fidei zu stabilieren die der Papst nach der Wahl abzulegen hätte. Sie war eine Erweiterung der angeblichen Professio fidei Bonifaz VIII., jener Fälschung, die, wie ich anderswo ausgeführt habe ${ }^{2}$ ), kurz zuvor, im Jahre 1407, an der Kurie Gregors XII. entstanden sein dürfte. Aber die eingeschobenen Zusätze wurden bereits. durch eine minder kardinalsfreundliche 2 . Kommission wieder beseitigt. Wenigstens retteten die Kardinäle ihr Wahlrecht, wenn sie es auch für dieses eine Mal mit anderen teilen mußten.

1) Hübler, Konstanzer Reform (1867), 129, 166, 195, 208.

2) MIÖG. XXXI (1910), 375 ff. : Die Entstehung der angeblichen Professio fidei Papst Bonifaz' VIII. 
Durch die am 11. November 1417 erfolgte Erhebung Oddo Colonnas als Martin V. hatte die Christenheit wieder einen einzigen Papst, das Kollegium ein Haupt. Papst und Kardinälen gelang nun die völlige Hintertreibung der gefürchteten Kirchenreform.

Wie das Papsttum nunmehr, befreit von dem Druck einer weltlichen Macht, wieder erstarkte, dadurch daß dasselbe Konzil, welches es durch Absetzung dreier Träger der Würde am tiefsten gedemütigt hatte, einheitlich und unbestritten alle päpstliche Gewalt in eime Hand zurlicklegte, so gewann der Kardinalat aus seiner alten, jetzt fest gewordenen Wurzel neue Kräfte - auch für sein Fundamentalrecht: der alleinige Besitz des Papstwahlrechtes ist ihm nicht noch einmal angegetastet worden. Aber durch dieselbe Erstarkung des Papsttums war das weitere Aufwärtsstreben des Kardinalats in der Gesamtheit unterbunden. Machttendenzen der Kardinäle hatten dem Schisma zum Ausbruch verholfen, seine Beendigung führte die endgiltige Untergrabung ihrer Kraft mit sich.

Jahrhunderte lang konnten die Kardinäle die glänzende Stellung nicht vergessen, die sie in den letzten Jahrzehnten des Schismas eingenommen hatten. Zeugen der Fortdauer dieser mit vergrößernder Kraft fortwirkenden Erinnerung sind die Versuche, in der Periode der Machtdekadenz des Kardinalats die längst entschwundene - in Wahrheit nur von Frankreich entliehene - Macht aus der Sehismazeit wieder zurückzuerlangen durch die Wahlkapitulationen, die mit dem nächsten Konklave wieder beginnen und sich $21 / 2$ Jahrhunderte hindurch fast ununterbrochen fortsetzen.

Sie knüpfen an die tatsächliche Redeutung der Kapitulationen des Schismas an; in ihnen liegt meiner Ansicht nach der höchste Ausdruck der Machtbestrebungen des Kardinalats ${ }^{1}$ ). Sie stellen gewissermaßen Versucbe dar, von der Sedisvakanz aus, in der die Kardinäle kraft ihres Fundamentalrechts mindestens teilweise die Verfügung über die päpstliche Macht hatten, überzugreifen in die Zeit der Stuhlbesetzung.

$\mathrm{Da} \beta$ die Kapitulationen, deren Kenntnis zum Verständnis mancher päpstlicher Regierungshandlungen erforderlich ist, rechtsverbindliche Kraft besaßen, haben mehrere Päpste teils durch bestätigende Konstitutionen, teils durch modifizierende Verfügungen ausdrücklich anerkannt.

Gegen die Nichtbeobachtung der Kapitulationen durch die Päpste, die sie beschworen hatten, hat sich in der Mitte des 16. Jahrhunderts eine laute, protestierende Stimme aus dem unterdrückten Kardinals-

1) Geringeren Wert mißt ihnen L. v. Pastor bei, z. B: in Geschichte der Päpste IIs, 307. 
kolleg erhoben, nach dem Tode Papst Pauls IV. 1559, der französische Dekan des Kollegs Jean du Bellay. In einem Promemoria hält er den Meineidigen vor: Wie Gott sich keines Eidbruches schuldig gemacht habe, so hätten auch die Päpste kein Recht zu einem solchen. Hielten sie doch die Verträge und Konkordate mit fremden Staaten. Warum nicht auch die mit uns abgeschlossenen? Und er gibt sich selbst darauf die Antwort, welche schon die Papstwähler im Schisma sich hätten sagen sollen: Weil wir keine Macht besitzen, weil wir nur den Eid haben.

Der Protest Du Bellays ${ }^{1}$ ) verhallte wirkungslos in der fortschreitenden Entwicklung des Papsttums zum völligen Absolutismus. Wenige Jahrzente später (1588) verstand Sixtus V. es, die Geschlossenheit des Kardinalskollegs zu brechen, indem er es durch Einrichtung der ständigen Kardinalskongregationen teilte, dabei einer notwendigen Verwaltungsreform Rechnung tragend. Das Kollegium, dessen Mitgliederzahl auf 70 gesteigert wurde, erhielt damit ausschließlich den Charakter eines kurialen Beamteninstituts.

Trotz alledem verblieben die Wahlkapitulationen noch über ein Jahrhundert hindurch, wenn anch nur wenige der im Konklave versammelten Papstwähler sich wirklich für sie interessierten.

Einer der letzten Kardinäle, der ihnen einen wirklichen Wert beimaß, war Benedetto Odescalchi im Konklave des J. 1676. Nach erfolgter Wahlentscheidung machte der Gewählte — es war Odescalchi selbst also der Papst zur Bedingung seiner Wahlannahme die Unterzeichnung und Beschwörung der Kapitulation durch die Kardinäle, soweit sie noch nicht unterzeichnet hatten. Das Verhältnis war also gegen den früheren Brauch gerade ungekehrt worden. Die Kapitulation war zweifellos das Werk Odescalchis, der seine Erhebung nicht geahnt hatte. Gewählt betrachtete Innocenz XI. sie gemäß meiner Interpretation ${ }^{2}$ ) als sein Regierungsprogramm, gewissermaßen als seine Thronrede, auf die er nun seine Mitarbeiter, die Kardinäle, verpflichtete. Nach diesem Vorgange hatten die Kapitulationen ihre alte Bedeutung naturgemäß völlig verloren. Ihre Entwicklung verlief im Sande. Die Geschichte der Machtbestrebungen des Kardinalskollegiums gegenüber dem Papsttume endigt mit jenem Dokumente Odescalchis.

1) Er wirft den Päpsten auch die schon auf dem Kostanzer Konzil in den Capita agendorum gerügte, willkürliche Anwendung der Formel: ,Cum consilio ,et consensu' fratrum nostrorum' vor.

2) Vgl. Päpstl. Wahlkapitulationen in Quellen und Forschungen des k. Preuss. Hist. Institutes in Rom XIL (1909), 231. 
Ist es nicht eine merkwürdige Inkonsequenz, daß schließlich die letzte der Wablkapitulationen, in denen jene Machtbestrebungen ihren Ausdruck gefunden hatten, von einem Papste als sein Regierungsprogramm benutzt wurde, auf das er seinerseits die Kardinäle durch Unterschrift verpflichtete? Und doch ist die Inkonsequenz nur scheinbar. Daß das Programm eines sachlich denkenden Kardinals und Kardinalskollegiums mit dem Regierungsprogramm eines Papstes, der seiner hohen Pflichten voll bewußt war, zusammenfiel, war das beredteste Zeugnis für die nunmehrige Stellung der Kardinäle. Diese hatten ihre Aufgabe ausschlieBlich im Dienste der Kirche gefunden, und damit war ihre Aufgabe mit der des Papsttums identisch geworden. Als erste Stützen des Papstes, im Dienste der Kirche, deren erste und zuverlässigste Beamte die Kardinäle geworden waren, haben sie nunmehr unentwegt zu ihrem inneren Ausbau und zu ihrem Gedeihen mitgearbeitet. 